\title{
Consideraçôes metodológicas sobre as possibilidades de aplicação da técnica de observação participante na Saúde Coletiva
}

| ${ }^{1}$ Fernando Manuel Bessa Fernandes, ${ }^{2}$ Marcelo Rasga Moreira |

Resumo: O presente artigo dirige-se a alunos, docentes e pesquisadores da Saúde Coletiva, e tem por objetivo contribuir para o debate sobre as possibilidades de aplicação da técnica de observação participante na pesquisa social em saúde, fornecendo especialmente a alunos de pós-graduação em Saúde Pública (strictu e lato sensu) subsídios teóricometodológicos e prático-instrumentais para a sua compreensão. A motivação provém da experiência acadêmico-profissional dos autores, com destaque para a docência da disciplina "Metodologia de pesquisa social II: as técnicas de levantamento de informação", do Programa de Pós-Graduação em Saúde Coletiva do DCS/ENSP/Fiocruz, nas modalidades strictu e lato sensu.

> Palavras-chave: pesquisa em saúde; pesquisa social; observação participante; técnicas de pesquisa social; técnicas de levantamento de informação.

\author{
1 Pesquisador e docente \\ contratado do Departamento \\ de Ciências Sociais da Escola \\ Nacional de Saúde Pública \\ Sergio Arouca da Fundação \\ Oswaldo Cruz (DCS/ENSP/ \\ FIOCRUZ). Endereço eletrônico: \\ fernando.bessa@ensp.fiocruz.br \\ 2 Pesquisador e docente \\ concursado do DCS/ESNP/ \\ FIOCRUZ. Endereço eletrônico: \\ rasga@ensp.fiocruz.br
}

Recebido em: 17/05/2012 Aprovado em: 28/05/2013 
A vida é breve; a arte é longa; a ocasião, fugidia; a experiência, enganosa; o julgamento, difícil.

Hipócrates de Cos

\section{Introdução}

Este artigo tem por objetivo tecer algumas considerações sobre a técnica de investigação chamada observação participante, fornecendo especialmente a alunos de pós-graduação em Saúde Pública (Strictu e Lato Sensu) subsídios para a compreensão, dos pontos de vista teórico-metodológico e prático-instrumental, de suas possibilidades de aplicação na pesquisa em Saúde.

A motivação para a confecção do artigo provém da experiência dos autores como docentes da disciplina "Metodologia de pesquisa social II: as técnicas de levantamento de informação", do Programa de Pós-Graduação em Saúde Pública do Departamento de Ciências Sociais da Escola Nacional de Saúde Pública Sergio Arouca, da Fundação Oswaldo Cruz (ENSP/Fiocruz).

No cotidiano da prática docente, é bastante comum alunos apresentarem dúvidas e enfrentarem dificuldades metodológicas decorrentes da relação pesquisador/objeto, assim como da utilização de técnicas de investigação ou de pesquisa em seus projetos. Em conjugação a isso, conforme já apontado por vários autores (DESLANDES, 1997; SERAPIONI, 2000; TEIXEIRA, 2004; COSTA, 2002), têm-se destacado, cada vez mais, na área da Saúde, a importância e a pertinência dos recursos metodológicos das Ciências Sociais e, mais especificamente, do arsenal teórico-instrumental da Antropologia.

Daí a necessidade cada vez mais nítida e crescente de subsidiar os alunos no sentido de aprofundarem sua compreensão acerca dos métodos e, principalmente, das técnicas de investigação ou pesquisa ditas de caráter qualitativo. Como pensar a observação participante na Saúde Coletiva? Que elementos seriam fundamentais para serem debatidos a respeito de seu emprego no cotidiano de pesquisa e trabalho na área da Saúde? Essas são questôes de partida que nos levam a refletir sobre como se pensa e se faz pesquisa em Saúde.

\section{Sobre metodologia, métodos, técnicas e campo de pesquisa}

Da experiência em sala de aula, nota-se que entre os alunos afloram, com regularidade, questões tais como: o que efetivamente são e quais são os limites dos métodos e das técnicas? Quando e em quais condiçôes devem ou não ser 
aplicados? Como lidar com as questões éticas e de objetividade/subjetividade/ intersubjetividade típicas de uma técnica como a observação participante? Existiria uma forma "correta" de utilizar essa técnica? É possível empregar instrumentais teórico-metodológicos quantitativos e qualitativos? Questões pertinentes e válidas, sem dúvida.

Sobre elas, são cabíveis inicialmente alguns esclarecimentos de ordem conceitual. "Metodologia" está definida neste artigo como o estudo sobre o método, a reflexão que os pesquisadores fazem sobre as estratégias, técnicas e categorias analíticas que desenvolvem em sua pesquisa, o que a caracteriza como um "conhecimento de segunda ordem", uma filosofia da ciência ou mesmo epistemologia. Já por "método", aqui se entende um "caminho" a ser construído e percorrido pelo pesquisador/investigador para atingir os objetivos de sua pesquisa, abarcando as dimensões teóricas, técnicas, éticas e criativas.

Entendemos, conforme diversos autores (SERAPIONI, 2000; MINAYOGOMEZ, 1997; MINAYO, 2004; CRUZ NETO, 1998), que é lícito dizer que a escolha dos métodos de pesquisa (e, por extensão, as técnicas a eles relacionadas) está impregnada de significado por conta de sua relação intrínseca com a orientação teórica e ideológica do pesquisador. À luz dessa afirmação, à primeira vista, quando comparadas entre si, as naturezas dos métodos quantitativo e qualitativo seriam, de per si, contraditórias, como alguns autores sustentam. Seria esse um aforismo irrefutável?

$\mathrm{O}$ debate entre pesquisa quantitativa e qualitativa, que vários pesquisadores consideram uma falsa querela por compreendem que ambas as abordagens são complementares, apesar de tudo, continua sendo uma realidade na prática da pesquisa (MINAYO; SANCHES, 1993; DUARTE, 2002). Entretanto, percebemos que é durante o exercício metodológico chamado de "recorte" do objeto (que define "o que" vai ser estudado) e a construção dos objetivos (o "para que" estudar o objeto), que se consolida o caráter qualitativo ou quantitativo de uma investigação.

Parece lógico que a conduta científica se encaminhasse para a complementação de ambas as dimensões, mas, como sua origem está indissoluvelmente vinculada a uma pesquisa que considera a subjetividade um problema, um empecilho até, as resistências são muitas e manifestam-se de diferentes maneiras, umas mais radicais, outras mais moderadas. 
Minayo e Sanches (1993) afirmam que a diferença entre qualitativo e quantitativo é de natureza:

[...] [E]nquanto cientistas sociais que trabalham com estatística apreendem dos fenômenos apenas a região visível, ecológica, morfológica e concreta, a abordagem qualitativa aprofunda-se no mundo dos significados das açôes e relações humanas, um lado não perceptível e não captável em equações, médias e estatísticas.

Procurando ampliar essa visão, é importante que se frise que aqueles que utilizam a abordagem qualitativa consideram que é pela intensificação da interação do investigador com os sujeitos pesquisados que se chega ao conhecimento científico. Por outro lado, muitos dos que advogam a abordagem quantitativa tendem a considerar que, por estar marcada pela subjetividade, essa interação é essencialmente problemática para a ciência, entendida como preocupada em estabelecer ordens e construir modelos sistêmicos analítico-explicativos do real - tomado como mensurável e passível de compreensão e tratamento por meio de quantidades e relaçôes numéricas, via linguagem matemática.

De ambas as partes, os pesquisadores têm desenvolvido técnicas para aperfeiçoar suas abordagens: os "qualitativos", para evidenciar a subjetividade nas relaçôes, incluindo-a como variável a ser analisada; os "quantitativos", para cada vez mais afastar os chamados "vieses subjetivos" das informaçôes levantadas. Isso, porém, não quer dizer que inexiste a possibilidade de conjugação das duas abordagens, dada a própria dinâmica do processo científico. Segundo Durkheim (1978), “[...] com relação ao método, nunca se pode fazer mais do que algo provisório, pois ele se modifica à medida que a ciência avança”.

A complementaridade de ambas pode ocorrer na medida da necessidade de utilização do instrumental de um ou outro método, derivada da questão ou hipótese com a qual o pesquisador se propõe trabalhar, tendo sempre em vista os objetivos e o objeto em tela. Como dizem Moreira e seus colaboradores (2002; 2003):

A iniciativa de conciliação operacional das dimensões mensuráveis e não mensuráveis da realidade visa responder, por um lado, à dificuldade das análises qualitativas em trabalharem com indicadores de resultados e impactos e, por outro, ao que Richardson frisa como uma das principais limitações das pesquisas essencialmente quantitativas: a análise e a comparação de dados e indicadores deslocados das relaçôes humanas que os produzem. 
Logo, essa iniciativa significa encarar os elementos humanos - a razão de ser das preocupações de profissionais das áreas de conhecimento ligadas à saúde como sujeitos e protagonistas de seu processo histórico.

A atividade de pesquisa implica, resumidamente, realizar uma seleção, ao delimitar o campo de pesquisa, e recortar o objeto a ser investigado/ analisado. Nesse processo, técnicas podem ser entendidas como ferramentas ou procedimentos sistematizados que o pesquisador realiza para obter as informações necessárias (chamadas de técnicas de investigação e/ou levantamento), organizálas, trabalhá-las e analisá-las a fim de atingir seus objetivos. Neste artigo, não se enfocarão técnicas estatísticas de processamento ou análise de dados.

Do ponto de vista do método, ou seja, do caminho trilhado pelo pesquisador, as técnicas de investigação começam a ser definidas desde o momento em que se recorta o objeto a ser pesquisado. Contudo, o momento em que elas afloram e que sua definição se torna mais premente é aquele no qual os objetivos da pesquisa são definidos. Isso significa que as técnicas de investigação não possuem autonomia metodológica para definir o objeto ou os objetivos de uma pesquisa. Em outras palavras: não se parte de uma técnica para se construir um objetivo ou um objeto. Esse, aliás, é um equívoco muito comum entre os alunos - e, por vezes, entre pesquisadores neófitos ou mesmo entre os experientes.

$\mathrm{Na}$ verdade, são os objetivos específicos de uma investigação que norteiam a escolha e a aplicação das técnicas. As informações que elas levantam, submetidas a análise, levam o pesquisador a conhecer melhor seu objeto de estudo, aprimorando-o. Pode até ser que, ao ampliar esse conhecimento sobre o objeto, o pesquisador reestruture seus objetivos, necessitando de novas informações e, portanto, aplicando novas técnicas de levantamento de dados.

Se assumirmos que o pesquisador é um sujeito, constatamos que ele está condicionado a desenvolver o caminho por ele trilhado na pesquisa. Tal caminho encontra pontos de confluência com a noção de campo de pesquisa, sobre a qual cumpre fazer algumas consideraçôes. Trata-se de uma construção intelectual do pesquisador a partir da realidade, na qual ele situa o seu objeto de investigação (MINAYO; SANCHES, 2003):

Entendemos por campo, na pesquisa qualitativa, o recorte espacial que corresponde à abrangência, em termos empíricos, do recorte teórico correspondente ao objeto da investigação [...]. A pesquisa social trabalha com gente, com atores sociais em 
relação, com grupos específicos. Esses sujeitos de investigação, primeiramente, são construídos teoricamente enquanto componentes do objeto de estudo. No campo, fazem parte de uma relação de intersubjetividade, de interação social com o pesquisador, daí resultando um produto novo e confrontante tanto com a realidade concreta como com as hipóteses e pressupostos teóricos, num processo mais amplo de construção de conhecimentos.

Campo de pesquisa, assim, é aqui entendido por um modelo mental de leitura tridimensional da realidade por parte do pesquisador: o espaço concreto onde acontece a aplicação das técnicas, o tempo necessário para tanto e as relações sociais que ocorrem entre os sujeitos investigados que nele estão. $O$ campo de pesquisa, portanto, deve ser entendido como um dado a mais para a investigação.

Com os avanços tecnológicos na área de telecomunicaçōes, as opções de contato entre as pessoas se expandem, sendo o advento da rede mundial de computadores - Internet, redes sociais e seus recursos de troca de mensagens a distância, em tempo real ou não - um novo e imenso "campo" a ser explorado.

Poderosas e prolíficas ferramentas de busca, fóruns e redes sociais e de relacionamento que abarcam milhões de usuários simultaneamente, todas essas inovaçōes que vêm ocorrendo nas últimas décadas têm-se mostrado, cada vez mais, possibilidades de intercâmbio de informações marcadas pela virtualidade, ou seja, o contato entre indivíduos de forma impessoal, no sentido de que não partem do pressuposto de que seja necessária e imprescindível a interação física entre as pessoas. Diante disso, o pesquisador deve estar atento para o fato de que sua simples presença e ação, mesmo no assim chamado mundo virtual, interfere na rotina e na vida dos sujeitos investigados, o que torna a investigação uma prática revestida de cuidados e responsabilidades para com todos aqueles que estão participando.

Mas o pesquisador não vai a campo como uma tábula rasa onde as informações se inscreverão ou se revelarão automaticamente. Sua própria bagagem cultural e suas subjetividades, do mesmo modo que as dos sujeitos investigados, devem ser consideradas. Quando se lida com questôes do âmbito da saúde, não poderia ser diferente, dado que sabemos que "qualquer ser humano, grupo ou classe social é uma multiplicidade de relações e de relações entre relações" (MINAYO; SANCHES, 1993). Para tanto e portanto, o pesquisador lança mão de técnicas de investigação, nunca esquecendo que elas devem sempre estar 1) de acordo com os seus objetivos na pesquisa a ser feita e 2) adequadas tanto ao campo de pesquisa como ao objeto recortados. 
Ao pesquisador, cabe construir seu próprio caminho, ou seja, seu método, utilizando para isso seu arcabouço teórico e seu instrumental concretizado nas técnicas das quais lançará mão em sua ida ao campo de pesquisa. Não pode, no entanto, desdenhar das reflexôes metodológicas existentes nem querer impor sua opção como a melhor ou a correta. Deve estar disposto a investigar, analisar, debater e promover o debate e, ao olhar para trás, enxergar em suas pegadas e rastros contribuições para o conhecimento, o saber, a ética e a melhoria das condições de vida e atendimento da população.

Feitas essas considerações, discorrer-se-á sobre a técnica de observação participante, aqui tomada como representante das técnicas de levantamento de informações, iniciando-se com uma breve gênese de sua utilização no âmbito da Antropologia, prosseguindo com o seu desenvolvimento ao longo do tempo e finalizando com algumas reflexôes sobre as possibilidades de sua aplicação na pesquisa na Saúde Coletiva.

\section{Sobre a técnica de observação participante}

A Antropologia surge e consolida-se como disciplina acadêmica do quadro das Ciências Humanas e Sociais no contexto do imperialismo político-econômico europeu da virada do século XIX para o XX, de cunho hegemonicamente etnocêntrico, positivista e evolucionista, preocupando-se com o estudo da origem do homem dito civilizado (GODOY, 2004).

Nas décadas iniciais do século XX, a corrente de pensamento que alcançava grande destaque no cenário da Antropologia e das Ciências Sociais em geral era o Funcionalismo, que postulava que as sociedades se caracterizariam pela semelhança com o corpo humano. As instituições perfazeriam funções satisfazedoras das necessidades dos homens e mantenedoras da organicidade do todo social, deixando pouco ou nenhum espaço para a ocorrência de conflitos, vistos como disfunções indesejáveis e demandantes de “cura”. Ao compreender-se o funcionamento das instituições de uma determinada sociedade, os funcionalistas acreditavam que se chegaria ao entendimento da cultura praticada por ela e se poderia "dissecá-la” e compreendê-la em sua totalidade. Abria-se, dessa forma, espaço para a ratificação científica da dominação europeia no mundo.

Inicialmente compreendida como uma técnica possibilitadora do acesso ao conhecimento da estruturação e do funcionamento de sociedades da África, 
Ásia, Oceania e das Américas, a observação participante sistematizou-se por intermédio do polonês radicado na Inglaterra Bronislaw Kasper Malinowski.

Com sua investigação realizada entre 1914 e 1918 junto aos nativos do arquipélago Trobriand, situado na Melanésia, região ocidental do Oceano Pacífico (MALINOWSKI, 1984), Malinowski é reconhecido como o implementador das bases da observação participante no trabalho de campo ou etnográfico em Antropologia. Apontou, entre outras, a necessidade de se anotarem as observações em um diário de campo, de se prestar atenção às situações esperadas e inesperadas do dia a dia, e de aprender a língua e os costumes dos sujeitos observados, os chamados "nativos".

A expressão "imponderáveis da vida cotidiana” tornou-se clássica nas Ciências Sociais por intermédio de Malinowski, que a cunhou para abarcar elementos observáveis do dia a dia que não eram levados em consideração para entender o funcionamento da sociedade. Seriam aqueles pequeninos gestos elementares que não têm substancialidade ou concretude imediata, mas que portam significados consistentes para a compreensão de aspectos culturais do grupo estudado.

Com o passar dos anos, os paradigmas do relativismo cultural das décadas de 50 e 60, do modernismo das décadas de 70 e 80 e do pós-modernismo dos anos 90 (GODOY, 2004; LACERDA, 2001) influenciaram a utilização da observação participante, trespassada por discussões teórico-metodológicas que ora pregavam o frio distanciamento do pesquisador, tido como neutro e objetivo investigador da realidade passível de total apreensão mediante treinamento científico, ora defendiam o caloroso contato e a interação com os sujeitos observados.

Atualmente, pensa-se ser possível afirmar de forma sintética que a observação participante se caracteriza pela promoção de interatividade entre o pesquisador, os sujeitos observados e o contexto no qual eles vivem. A pesquisa dita qualitativa - e dentre todas as suas técnicas, em particular, a observação participante - obriga o pesquisador a lidar com o "outro", num verdadeiro exercício constante de respeito à alteridade. Pressupõe convívio e intercâmbio de experiências primordialmente através dos sentidos humanos: olhar, falar, sentir, vivenciar, experimentar.

É forçoso concordar que a prática da observação participante se insere naquilo que Rubem Oliven (1980) diz sobre a prática da própria Antropologia: “[...] a Antropologia, para ser uma boa Antropologia [...] necessita ser radical, no sentido etimológico do termo, isto é, procurar ir à raiz dos fenômenos que estuda, sem ter medo de desafiar tabus e conhecimentos consagrados". 
Mariza Peirano, em seu livro A Favor da Etnografia (1995), como o nome

já sugere, defende e discute profundamente o ofício do antropólogo em sua experiência no campo. Ela adverte: não há como ensinar a fazer pesquisa de campo, uma vez que ela depende de variáveis imprevisíveis que vão desde as escolhas teóricas do pesquisador, passando pelos imponderáveis da vida cotidiana verificáveis em campo, até a biografia do próprio etnógrafo.

Por meio do contato direto, a observação participante estabelece relações informais entre os sujeitos observados e o pesquisador, que lança mão de recursos variados para a coleta e análise de informações e dados:

- Um roteiro de campo, no qual previamente o pesquisador estabelece diretrizes a serem exploradas, quer dizer, as questôes que se deve observar de acordo com os objetivos da pesquisa, sem a preocupação de segui-las com rigidez absoluta, deixando espaço para "imponderáveis", situações inesperadas (MALINOWSKI, 1984) e insights (NICOLÁS, 1984) - "estalos”, percepções do pesquisador a partir de determinadas situações, fatos, diálogos ou lembranças, estabelecendo conexões lógicas entre dois ou mais elementos.

- Um diário de campo, no qual o pesquisador registra suas impressóes sobre o cotidiano dos sujeitos observados, atentando para o fato de que aquilo que se anota ainda não é dado científico, pois surge a partir da submissão das informações coletadas às categorias de análise construídas pela reflexão teórica;

- Informante(s)-chave: um ou vários sujeitos observados (uma "rede"), que apresenta $(\mathrm{m})$ para o pesquisador atributos para facilitar a obtenção de dados, dada sua inserção no meio onde a observação se processa. Pode(m) abrir ou fechar portas e caminhos para a pesquisa, dependendo do desenvolvimento da relação estabelecida com e pelo pesquisador;

- Gravador(es) ou câmera(s), recursos tecnológicos auxiliares da observação, que possibilitam a captação de dados audiovisuais, contribuindo para dar suporte e apoio complementar à memória e ao diário de campo do pesquisador.

Percebe-se que há muitas possibilidades e caminhos a serem abertos para que os pesquisadores lancem mão de recursos tecnológicos auxiliares na observação, tais como gravadores e câmeras, que não só podem como devem ser utilizados, principalmente, dada a sua capacidade de captar informaçôes preciosas contidas nas falas e no gestual dos sujeitos observados. 
A utilização pura e simples de todos esses recursos, no entanto, não se consubstancia em sucesso na aplicação da técnica. Realizar uma observação participante demanda ao pesquisador, em primeira e última instância, um forte investimento teórico-metodológico. Segundo Evans-Pritchard (1978),

[...] a primeira exigência para que se possa realizar uma pesquisa de campo é um treinamento rigoroso, para que se saiba como e o que observar, e o que é teoricamente significante [...]. Não se pode estudar nada sem uma teoria. Por outro lado, o antropólogo deve seguir o que encontra na sociedade que escolhe estudar: a organização social, os valores e sentimentos do povo, e assim por diante.

Daí torna-se imperativo lembrar que "é preciso desconfiar sempre das primeiras impressões" (VELHO, 1980), visto que nem sempre o essencial é imediatamente visível. Além disso, pode-se extrair uma noção que não convém ser esquecida: todos os dados obtidos pela observação participante advêm da conjugação da tríade participação do pesquisador, ação dos sujeitos observados e situação contextual.

No entender dos autores, talvez a técnica de observação participante seja mais bem ilustrada pela principal demanda feita ao pesquisador disposto a utilizá-la: a adequação comportamental ao grupo que será observado, ou seja, a convicção de que, por necessariamente implicar convívio, observação participante significa, em última análise, vivência de tensões.

A presença do pesquisador no campo, por mais discreta que seja sua observação, é participação. Ambas são entendidas como polos do eixo de presença ilustrado no quadro abaixo.

\section{Quadro 1. Posicionamento do Pesquisador em Campo ao empregar a Técnica de Observação Participante}

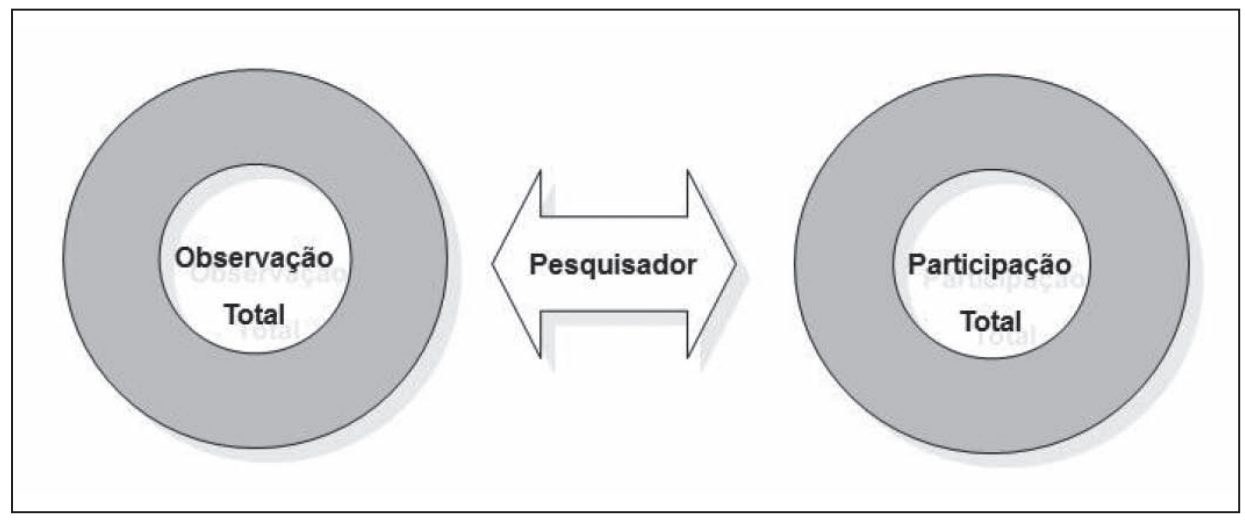

Fonte: Própria 
Não é facultada ao pesquisador uma participação total, ou seja, o pesquisador nunca deixará de ser um estranho, dado que assume uma conduta diferenciada dos sujeitos investigados. Porém, a participação total pode ser alcançada, sob pena de se abstrair o propósito do qual o pesquisador estava imbuído. Em outras palavras, é possível participação total, mas isso significa abrir mão da pesquisa.

Em contrapartida, é também inalcançável o polo da observação total, "pura", por conta do fato de que a presença do pesquisador está intrínseca ao campo de pesquisa. Logo, o profissional deve estar consciente de que, o tempo todo, perfaz um movimento pendular nesse eixo, aproximando-se ora da participação, ora da observação, quando a interação com os sujeitos investigados assim o exige.

$\mathrm{Na}$ observação participante, portanto, o pesquisador obrigatoriamente encontra-se na zona intersticial entre os dois polos, mas nunca alcançando a plenitude de um deles, pois o famoso bias, ou "viés", sempre estará presente nas investigações. Mas isso não é algo para se lamentar, pois faz parte de nossas vidas, o tempo inteiro. Cabe, sim, ao pesquisador, torná-lo seu aliado na compreensão do seu objeto por meio do rigor metodológico, e não tratá-lo como inimigo ou elemento indesejável que "contamina" a investigação.

A observação total, isenta, asséptica, "neutra", nos moldes clássicos das ciências duras, simplesmente não é possível porque o pesquisador inevitavelmente influencia e é influenciado pelo campo de pesquisa e pelos sujeitos investigados, por se encontrar vivenciando interatividade.

Já a participação total, ou seja, a identificação total com os sujeitos investigados, também é impossível ao pesquisador, dada a diferença que inexoravelmente o marca e distingue dos sujeitos investigados: sua postura investigativa, pautada pelo rigor metodológico. E é por isso que não é possível estabelecer receitas ou manuais que listem, rígida e dogmaticamente, os procedimentos supostamente corretos nessa técnica, conforme nos alertam alguns autores da Antropologia: "Como veem, não há uma única resposta - muito depende da pessoa, da sociedade que estuda e das condições em que tem de fazê-lo...” (EVANS-PRITCHARD, 1978); ou ainda,

[...] para realizar seu trabalho, [o pesquisador] precisa permanentemente manter uma atitude de estranhamento diante do que se passa não só a sua volta como com ele mesmo. Não encaro isso como uma superioridade, mas como uma especificidade [...]. O movimento mais dramático coloca-se quando [o pesquisador] se volta para o seu próprio cotidiano nesse processo de estranhamento. Isso é possível, sem necessa- 
riamente levar à loucura, porque a vida social e a cultura se dão em múltiplos planos, em várias realidades que estão referidas a níveis institucionais distintos. O indivíduo na sociedade moderna move-se entre esses planos, realidades níveis e constitui sua própria identidade em função desse movimento. (VELHO, 1980, grifo nosso).

Essa contingência do emprego da técnica permite refletir que, quando o campo ou o dia a dia da pesquisa coincide com locais considerados problemáticos (áreas geográficas ou ambientes profissionais com alto grau de risco de deflagração de conflitos dos mais variados tipos), o bom-senso faz-se imperativo.

Obviamente, não se espera que o pesquisador aja como um herói clássico, desprezando sua própria segurança frente aos perigos inerentes a situações como essas, martirizando-se em nome dos cânones da Ciência. Cabe, no entender dos autores, a adoção de uma postura francamente honesta e analítica no sentido de verificar as possibilidades de execução da pesquisa nos moldes nos quais ela está fundamentada, jamais se esquecendo de observar os princípios éticos da pesquisa com seres humanos.

Quanto a essa questão, existem códigos de Ética que norteiam a ação do pesquisador, auxiliando-o a realizar um trabalho condigno e respeitoso. O Código de Ética do Antropólogo, disponível no sítio eletrônico da Associação Brasileira de Antropologia (ABA, s/d), preconiza que são direitos das populações objeto de pesquisa a serem respeitados: 1) Direito de ser informadas sobre a natureza da pesquisa; 2) Direito de recusar-se a participar de uma pesquisa; 3) Direito de preservação de sua intimidade, de acordo com seus padrões culturais; 4) Garantia de que a colaboração prestada à investigação não seja utilizada com o intuito de prejudicar o grupo investigado; 5) Direito de acesso aos resultados da investigação; 6) Direito de autoria das populaçóes sobre sua própria produção cultural.

Em âmbito nacional, a atribuição de exame dos aspectos éticos das pesquisas que envolvem seres humanos é da Comissão Nacional de Ética em Pesquisa (CONEP), diretamente ligada ao Conselho Nacional de Saúde (CNS, s/d). Seguindo o mesmo diapasão, o Comitê de Ética em Pesquisa da Escola Nacional de Saúde Pública Sergio Arouca, da Fiocruz (CEP/ENSP), preconiza em seu sítio eletrônico que

[...] tem a atribuição de avaliar a eticidade dos projetos de pesquisa dos pesquisadores, tecnologistas e estudantes de Pós-Graduação da ENSP e de seus cursos descentralizados e interinstitucionais que sejam concernentes a seres humanos. (CEP, s/d). 
Tais preocupações são fundamentais e não devem jamais ser negligenciadas pelos pesquisadores em suas experiências de campo.

\section{Sobre como viabilizar a observação participante na pesquisa em Saúde Coletiva}

A observação participante apresenta potencialidade em facultar ao pesquisador a percepção de significados, representações, relações, normas, discursos, falas, sistemas de valores, símbolos, condições estruturais e dimensōes esperadas e inesperadas do problema que motivou a pesquisa (SERAPIONI, 2000; MINAYO; SANCHES, 1993; GEERTZ, 1978). Contudo, a escassez de tempo hábil para o desenvolvimento de uma investigação, situação com a qual muito comumente se deparam os profissionais da área de Saúde que têm esse propósito, faz com que a técnica seja passível de utilização, conquanto que operacionalizada em articulação com outras técnicas, sempre ancoradas nos objetivos da pesquisa.

Impõe-se a questão: até que ponto é válida e produz dados científicos consistentes uma observação participante operacionalizada em um período de tempo curto, como por exemplo, apenas um dia? Seria factível e viável uma pesquisa que lançasse mão dessa técnica nessas condições? Alguns autores demonstram que a observação participante realizada em um prazo generoso é propícia para o amadurecimento de ideias, noções e percepções, pois quanto mais dados observados reveladores de uma mesma perspectiva, maior é a validade da conclusão do trabalho. Por esse raciocínio, a partir de observações constantes e por um período de tempo considerado longo, torna-se mais nítido ao observador o modo de pensar e agir dos observados:

[...] observações numerosas feitas durante um período de tempo substancial ajudam o observador a se proteger contra seus biases conscientes ou inconscientes, contra "ver apenas o que ele quer”. Pois é igualmente difícil mentir para si mesmo. (BECKER, 1994).

Porém, é fato que a viabilidade do emprego da observação participante guarda íntimas conexóes com o investimento teórico, e que este influencia decisivamente a elaboração dos dispositivos analíticos do pesquisador. A dimensão temporal da permanência do pesquisador no campo liga-se aos objetivos e ao objeto, por sua vez, intrinsecamente conectados à concepção ideológica do pesquisador:

[...] Muitas vezes, quando perguntados sobre a especificidade do nosso trabalho denso das Ciências Sociais, acionamos o tema da observação participante, do con- 
vívio prolongado com os grupos estudados, com a paciente e perseverante estadia junto aos nativos. Sabemos, no entanto, que Lévi-Strauss passou semanas com os Nambiquara; Evans Pritchard, não mais de alguns meses com os Nuer; e que Marcel Mauss só realizou uma rápida viagem de estudos ao Marrocos, o que não impediu que construíssem obras ricas e definitivas. Seriam exceções, figuras ímpares, impossíveis de servirem de modelo devido a sua excepcionalidade? Ou seriam uma demonstração clara de que não há cânones nem regras rígidas em um trabalho que depende muito de sensibilidade e intuição? É claro que, por detrás dessas rápidas estadias (segundo padrões malinowskianos) existia um sólido conhecimento provindo de anos de estudo e preparação. Chega-se ao óbvio - é impossível fazer boa Antropologia sem ter um bom preparo teórico. Surgem outros problemas, no entanto: o que é um bom preparo teórico? [...] (VELHO, 1980).

Não se pode deixar de lado a noção de que há espaço para que se conjugue a observação participante com outras técnicas, como as de grupos focais ou de entrevista, no intuito de aprofundar questões que possam ter surgido durante a observação e que requeiram o uso daquelas ou de outras técnicas de investigação.

As situações nas quais a observação participante se faz necessária são aquelas onde o pesquisador tem que buscar o entendimento das relações entre pessoas e instituições, assim como as práticas estabelecidas, as visões de mundo e as opiniōes dos sujeitos investigados, elementos que não seriam (bem) captados por outras técnicas de investigação.

Há situações e informações dos e sobre os sujeitos investigados que não são facilmente comunicáveis por palavras, requisitando a sensibilidade do pesquisador para a compreensão de dimensões profundas e significativas que não são passíveis de ser enquadradas em variáveis (MINAYO; SANCHES, 1993; DURKHEIM, 1978). O pesquisador deve estar ciente, também, de que há fatos e situações que simplesmente não permitem o estudo através da observação participante, por dificultarem ou impedirem a presença do pesquisador no momento de sua ocorrência, ou logo depois dela (BECKER, 1994; RICHARDSON, 1999).

Se, enquanto a observação participante estiver sendo aplicada, o pesquisador sentir necessidade, por exemplo, de aprofundamento, de ouvir a fala dos sujeitos investigados, é sinal de que já é hora de se voltar para os seus objetivos e refletir sobre a adequação e a conveniência de outra técnica que dê conta dessa necessidade nesse caso, a entrevista. Se sentir necessidade de explorar algum tema ou conjunto de temas nos quais as falas dos sujeitos investigados são ouvidas em debate, a técnica de grupos focais talvez seja mais adequada (CRUZ NETO, 2001). 
O exercício do rigor metodológico deve demonstrar ao pesquisador que uma quantidade grande de tempo dispendido nem sempre é sinônimo de boa qualidade de informações, pois a dimensão temporal da permanência do pesquisador no campo de pesquisa liga-se ao objetivo da investigação. Quanto maior for a sua complexidade, quanto mais aspectos, rotinas, funções, profissionais em atividade, percursos de usuários no serviço, etc., houver no objetivo, mais tempo o pesquisador precisará passar em campo.

De modo inverso, uma massa de informações de boa qualidade pode ser obtida em uma quantidade de tempo mais reduzida, se o pesquisador tiver feito um forte investimento teórico-metodológico, articulando coerente e eficazmente o tempo em campo, seus objetivos e seu objeto. Lembramos Minayo (2004, p.235), que diz:

[...] não é o campo que traz o dado, na medida em que o dado não é 'dado', é 'construído'. É fruto de uma relação entre as questôes teoricamente elaboradas e dirigidas ao campo e num processo inconcluso de perguntas suscitadas pelo quadro empírico às referências teóricas do investigador.

O campo, os objetivos e o objeto, por sua vez, como já afirmado antes, são intrinsecamente conectados à percepção do pesquisador de saturação ou esgotamento das possibilidades de captar informaçóes. Quando isso acontece, o pesquisador deve, ao cogitar e definir a utilização de outras técnicas de investigação, repensar seus objetivos e seu objeto, a fim de realizar uma reflexão crítico-metodológica, em direção ao constante aperfeiçoamento de sua prática como pesquisador em Saúde e sujeito compromissado com a melhoria das condiçôes de vida da população.

Tendo refletido sobre essas questôes, outros autores apontam para a modalidade de observação em equipe. Nesse caso, existe a possibilidade de confrontação dos dados obtidos pelos diversos observadores, o que favorece o surgimento de uma riqueza na dimensão, no alcance e na variedade de observações efetuadas, já que todos os pesquisadores podem contemplar os mesmos aspectos ou particionar a observação. Assim, vários pesquisadores podem utilizar diferentes instrumentos (desde que necessários), implicando maior eficácia, eficiência e efetividade no cumprimento de prazos, metas e objetivos, ao mesmo tempo em que podem otimizar o tempo, conjugando técnicas diversas.

Há que se ponderar, entretanto, que nem sempre é possível para os alunos ou para os pesquisadores iniciantes não engajados numa linha ou grupo de pesquisa estabelecer e manter uma equipe para desenvolver a sua pesquisa. 
A utilização da observação em equipe passa, então, por três pontos principais: a disponibilidade de vários observadores, um tanto problemática diante da realidade acadêmica do país, com escassez de recursos financeiros e humanos; o investimento teórico-metodológico e prático na formação dos integrantes da equipe; e a importância em gerenciar a multiplicidade de visões, evitando que a pesquisa derive para uma situação de perda de unidade. Simone Guedes nos traz:

[...] [T] odos sabemos que cada trabalho de campo é uma experiência específica, impossível de ser repetida e, mesmo, dificilmente relatada, dificuldade proverbial dos antropólogos [...]. No meio urbano, contudo, esse lado se recupera de forma diversa, mais aventureiro e menos romântico quanto mais é 'outro', a nosso ver, o espaço social no qual entramos [...]. A presença de mais um pesquisador pode diluir o medo, mas não o elimina. Trabalhar com outras pessoas significa, também, ter com quem compartilhar as dúvidas do trabalho de campo, tão prementes quanto aquelas que acometem os pesquisadores solitários em aldeias longínquas. Mas significa igualmente multiplicar dificuldades. A maioria delas deriva da complexidade do sistema de relaçôes pessoais acionado pela pesquisa [...]. (GUEDES, 1997).

O debate está aberto. Assim como na vida, a criatividade do pesquisador torna-se uma preciosa e imprescindível aliada no âmbito do desenvolvimento das atividades de pesquisa.

Por fim, e por certo, cabe o pensamento de que a aplicação da observação participante em saúde é um grande e fascinante desafio, por obrigatoriamente pressupor interatividade e intersubjetividade envolvendo humanos, seres plásticos por essência, natureza e expressão de afetos. Em direção a isso, compreende-se que a aventura da busca pelo conhecimento na saúde deve encampar a proposta da humanização no trato entre e com indivíduos, encarados como pessoas-atores protagonistas de relações e condições de vida. ${ }^{1}$

\section{Referências}

ASSOCIAÇÃO BRASILEIRA DE ANTROPOLOGIA. [site da Internet] Disponível em: http://www.abant.org.br/quemsomos/codigo/codigo.shtm. Acesso em 15 fev 2012.

BECKER, H. Métodos de pesquisa em ciências sociais. 2a ed. São Paulo: Hucitec, 1994.

COMISSÃO NACIONAL DE ÉTICA EM PESQUISA. Conselho Nacional de Saúde/ CNS. [site da Internet] Disponível em: http://conselho.saude.gov.br/Web_comissoes/ conep/index.html. Acesso em 15 fev 2012. 
COMITÊ DE ÉTICA EM PESQUISA da Escola Nacional de Saúde Pública Sergio Arouca da Fiocruz. [site da Internet]. Disponível em: http://www.ensp.fiocruz.br/etica/index.cfm. Acesso em 15 fev 2012.

COSTA, M.C.S. Intersubjectivity and historicity: contributions from modern hermeneutics to ethnographic research. Rev Latino-Am Enfermagem, v.10, n.3, p.372-382, 2002.

CRUZ NETO, O. O trabalho de campo como descoberta e criação. In MINAYO C. S. Pesquisa social: teoria, método e criatividade. 10ª ed. Petrópolis: Vozes, 1998.

CRUZ NETO, O.; MOREIRA, M.R.; SUCENA, L.F.M. Grupos focais e pesquisa social: o debate orientado como técnica de investigação. Rio de Janeiro: Fiocruz, 2001.

DESLANDES, S.F. Concepções em pesquisa social: articulações com o campo da avaliação em serviços de saúde. Cad Saúde Pública, v.13, n.1, p.103-107,1997.

DUARTE, R. Pesquisa qualitativa: reflexões sobre o trabalho de campo. Cad Pesquisa, v.115, n.1, p.139-154, 2002.

DURKHEIM, E. As regras do método sociológico. São Paulo: Cia Editora Nacional, 1978.

EVANS-PRITCHARD, E.E. Bruxaria, oráculos e magia entre os azande. Rio de Janeiro: Zahar, 1978.

GEERTZ, C. A interpretação das culturas. Rio de Janeiro: Zahar, 1978.

GODOY, M.G.G. Os desafios da antropologia em favor da interdisciplinaridade. Tempo \& Memória, v.2, n.2, p.21-32, 2004.

GUEDES, S.L. Jogo de corpo: um estudo de construção social de trabalhadores. Niterói: EDUFF; 1997.

LACERDA, E.P. Trabalho de campo e relativismo. a alteridade como crítica da antropologia. Revista online quatrocantos.com. Abr-mai, 2001. [Online]. Disponível em: http://www. antropologia.com.br/arti/colab/a5-eplacerda.pdf. Acesso em: 15 fev 2012.

MALINOWSKI, B. Os argonautas do pacífico ocidental. São Paulo: Abril Cultural, 1984.

MINAYO, M.C.S. O desafio do conhecimento: pesquisa qualitativa em saúde. $8^{a}$ ed. São Paulo: Hucitec, 2004.

MINAYO, M.C.S.; SANCHES, O. Quantitative and qualitative methods: opposition or complementarity? Cadernos de Saúde Pública, v.9, n.3, p.237-248, 1993.

MINAYO-GOMEZ, C.; THEDIM-COSTA, S.M.F. A construção do campo da saúde do trabalhador: percurso e dilemas. Cad Saúde Pública, v.13, n.2, p.21-32, 1997.

MOREIRA, M.R.; CRUZ NETO, O.; SUCENA, L.F.M. A relação dos profissionais do programa saúde da família com o contexto de exclusão social da população atendida. Rev Saúde em Foco, v.23, p.65-81, 2002. 
MOREIRA, M.R.; FERNANDES, F.M.B.; SUCENA, L.F.M. Uma leitura sobre a avaliação de políticas públicas de saúde. In: CONGRESSO DE SAÚDE COLETIVA, 7, 2003; Brasília. p. 581-593.

NICOLÁS, J. Observação. In: Dicionário de Ciências Sociais. Rio de Janeiro: FGV, 1987.

OLIVEN, R.G. Por uma antropologia em cidades brasileiras. In: VELHO, G. O desafio da cidade: novas perspectivas da antropologia brasileira. Rio de Janeiro: Campus, 1980. p. 26-36. PEIRANO, M. A favor da etnografia. Rio de Janeiro: Relume-Dumará, 1995.

RICHARDSON, R. Pesquisa Social: métodos e técnicas. São Paulo: Atlas, 1999.

SERAPIONI, M. Métodos qualitativos e quantitativos na pesquisa social em saúde: algumas estratégias para a integração. Rev C S Col, v.5, n.1, p.187-192, 2000.

TEIXEIRA, M.O. As ciências sociais entre biólogos e vacinas: agruras do estudo em um laboratório. Hist. cienc. saude-Manguinhos, v.11, n.1, p.159-172, 2004.

VELHO, G. O antropólogo pesquisando em sua cidade: sobre conhecimento e heresia. In: . O desafio da cidade: novas perspectivas da antropologia brasileira. Rio de Janeiro:

Campus, 1980. p.13-23.

\section{Nota}

${ }^{1}$ F.M.B. Fernandes e M.R. Moreira participaram da coleta e da análise de dados, da discussão dos resultados e da redação final do artigo. 
Methodological considerations on the possibilities of application of the participant observation technique in Public Health Aimed at students, teachers and researchers of Public Health, this article searches to contribute to the debate on the possibilities of application of the technique of participant observation in social research in health, especially providing students in Health public (strictu and lato sensu) theoretical-methodological and practical and instrumental subsidies to understand this technique. The motivation comes from the academic and professional experience of the authors, with emphasis on teaching the course "Methodology of social research II: techniques of information", from the Post-Graduate Public Health DCS / ENSP / Fiocruz, in strictu and lato sensu modalities.

> Key words: health research; social research; participant observation; social research techniques; techniques of information. 